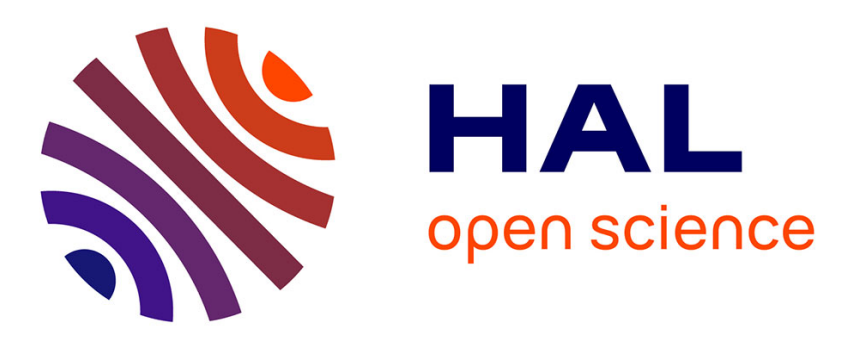

\title{
A process of design and production of Virtual Reality Learning Environments
}

Lahcen Oubahssi, Oussema Mahdi, Claudine Piau-Toffolon, Sébastien Iksal

\section{To cite this version:}

Lahcen Oubahssi, Oussema Mahdi, Claudine Piau-Toffolon, Sébastien Iksal. A process of design and production of Virtual Reality Learning Environments. International Conference on Collaborative Learning (ICL 2018), Sep 2018, Kos Island, Greece. pp.353-364. hal-01882158

\section{HAL Id: hal-01882158 \\ https://hal-univ-lemans.archives-ouvertes.fr/hal-01882158}

Submitted on 26 Sep 2018

HAL is a multi-disciplinary open access archive for the deposit and dissemination of scientific research documents, whether they are published or not. The documents may come from teaching and research institutions in France or abroad, or from public or private research centers.
L'archive ouverte pluridisciplinaire HAL, est destinée au dépôt et à la diffusion de documents scientifiques de niveau recherche, publiés ou non, émanant des établissements d'enseignement et de recherche français ou étrangers, des laboratoires publics ou privés. 


\title{
A process of design and production of Virtual Reality Learning Environments
}

\author{
Lahcen Oubahssi, Oussema Mahdi, Claudine Piau-Toffolon and Sébastien Iksal \\ Le Mans Université, LIUM, EA 4023 \\ Avenue Messiaen, 72085 LE MANS CEDEX 9, France \\ \{first_name.last_name\}@univ-lemans.fr
}

\begin{abstract}
Facilitating human learning is one of the uses of virtual reality (VR). Users interact within original and dynamic situations of learning in an integrated learning environment called Virtual Reality Learning Environment (VRLE). Nevertheless, the design of these environments is still considered as a complex task. We intend to study and propose technical and methodological solutions to help teachers to design (adapt or reuse) their pedagogical situation with a scenario-based approach and to operationalize it in a VR learning environment. In this work, we defined a design process allowing teachers to generate their VRLE. Then, we instantiated the proposed design process with a pedagogical situation as an illustrated example.
\end{abstract}

Keywords: Pedagogical Scenario, Learning Design, Educational Virtual Environments, Virtual Reality Learning Environments, Pedagogical Situation.

\section{Introduction}

Virtual reality is more than a new concept: it is emerging as a new medium with its own characteristics. Some of these characteristics include the ability to allow individuals to live an immersive experience, carry out a senso-motor activity in an artificial world, and interact with each other and with events that are unavailable or unrealistic due to distance, time, cost, or safety factors. These characteristics find a big interest in the scope of learning and are integrated in educational environments. Mikropoulos, and Natsis [1] define a Virtual Learning Environment (VLE) or Educational Virtual Environment (EVE) as a « virtual environment that is based on a certain pedagogical model, incorporates or implies one or more didactic objectives, provides users with experiences they would otherwise not be able to experience in the physical world and redounds specific learning outcomes ». To illustrate, in this research paper we propose a VRLE where learners may study the phenomenon of relativity of movement and the gravitational attraction. In this example, learners may visualize and interact with the three-dimensional virtual representation of the moon, the earth and the sun. They will, "experience the virtual environment in real-time, visualize abstract concepts, articulate their understanding of phenomena by constructing or manipulating the virtual environments and visualize the dynamic relationships between several variables in a virtual environment system" [2]. However, the VRLE design is a complex activity. The difficulties can be technical and cognitive 
at the same time [3] [4]. According to the model of technology integration, VRLE's design should combine three sources of knowledge: technology, pedagogy and content [5]. To fully describe the learning experience, designers have to describe a pedagogical scenario, its operationalization and the control of activities in the target virtual learning environment e.g the environment where the pedagogical situation is described. According to our literature study, we noticed that numerous VRLE environments depend, most of the time on a specific domain and context of learning. The scenario model has to be planned at the early stages of the environment's design where all possible situations have to be envisaged. This is often difficult for teachers. The existing environments are more intended for specialists in the virtual reality field. It is not easy for teachers to define and adapt the scenarios models according to their learning situations. Teaching is a design activity that may be considered as "the intelligent center of the whole teaching-learning lifecycle", open to transformation by the learners [6] and supported by process and tools [7]. There are few methods and tools helping and giving support to teachers for designing their own solution [8] and it is particularly true for VRLE. Therefore, designing a virtual learning situation is a complex task for the teachers and solutions are required to help them to design, to reuse and to spread their pedagogical scenarios in the VRLE. The research questions of this study are relative to the activity of design and operationalization of the pedagogical scenarios by the teachers - designers in the target VRLE. The main question is the following: how to help the teachers to express and formalize their learning situations, which are not dependent to a virtual reality-based environment? Once the pedagogical needs are formalized, how to operationalize/to spread them in VRLE by respecting the pedagogical intentions of teachers and by limiting the semantic losses? Our research efforts aim at developing methodological and technical tools to answer these questions. In this way, we propose an iterative design teacher-centered approach. Teacher's design practices are iterative, reflection may occur before, during and after a unit's implementation in a participatory approach [9] [8]. The rest of this paper is structured as follows. The second section presents some VRLE tools and environments selected according to our research interest. We analyze these tools according to design quality criteria [10]. In the next part, we propose a VRLE design process framework. To illustrate our approach, we report in the last section an experiment consisting of using an on-purpose pedagogical situation based on a virtual reality environment. Finally, we present some concluding remarks and the next steps of this project.

\section{Review of VRLEs literature}

In this literature review, we take a closer look at some VRLE and focus on their architectures, design models and learning scenario models. We examine the key strengths and limits of these proposals according to the research issues we mentioned in the previous section. 


\subsection{The different VRLEs design models}

The usual approach is to start with technical considerations before addressing pedagogical issues. For example, Trinh \& al. [11] provide models for the knowledge explanation of virtual agents populating virtual environments. This knowledge focuses on the structure and dynamics of the environment as well as procedures that teams can perform in this environment. This makes it possible to ensure the different semantic constraints in VR: 1) internal properties of the spatial object, 2) spatial relationships between a set of spatial objects, and 3) semantic of spatial interactions (for example, before and after the state of the spatial tasks). Chen \& al. [12] propose a theoretical framework to guide VRLEs' design. This framework is divided into two subsets. The first is called "macro-strategy". It refers to the overall design of the VRLEs and involves 1) identification of learning objectives (skills, knowledge, etc.) and the relationship between these objectives; 2) identification of pedagogical scenarios allowing the learner to acquire the targeted learning; 3 ) identification of the help provided to the learner (resource information, tools, etc.) to facilitate the acquisition of targeted learning. The second subset is called "micro-strategy". It refers to the pedagogical scenarios adaptation according to the type of VRLE that one wishes to design. Chen \& Teh [13] propose some improvements of the virtual environment pedagogical design model proposed in [12]. Ritz [14] provides guidelines for best practices in integrating immersive virtual reality, especially Cave Automatic Virtual Environment (CAVE), into teaching. These guidelines will address a practical need by informing and supporting educators in adapting instructional design to emerging technology. We note that the proposed design models are not easy to achieve for non-computer specialists.

\subsection{VRLEs learning scenario models}

Many studies in the field of VRLEs have addressed the issue of modeling pedagogical situations in virtual environments. For example, Sehaba \& Hussaan [4] propose a system that allows personalizing for each patient the running of virtual games for the evaluation and rehabilitation of cognitive disorders. Marion \& al [15] propose a learning scenario model POSEIDON able to integrate a VRLE in the learning process. The approach is based on meta-modeling ensuring the modeling genericity, regardless of the nature or domain of VRLEs. The authors use a meta-model that provides an abstract representation of virtual environments both generic and machine readable. Fahim \& al [16] ensured that the generic side of the POSVET pedagogical scenario model using the MASCARET meta-model, allows to reuse pedagogical scenarios on different platforms. We note that, MASCARET is a meta-model describing virtual environments and agents that evolve in this environment. This meta-model is based on UML that describes the structure of the environment (entities, positions), the entities and behaviors of agents [17]. The main POSVET advantage is to allow the adaptation of pedagogical activities and to offer to learners a control on their learning. This work aims at adapting the pedagogical scenario to the learners' needs but doesn't offer solutions for assisting the teachers in their design process. Chen \& al [12] as 
cited previously, propose a theoretical framework which identify four principles of pedagogical scenarios' realizations: 1) the conceptual principle that guides the learner towards the information to be considered; 2) the principle of metacognition that explains to the learner how to think during learning; 3) the procedural principle that indicates how to use the information available in the VRLEs; 4) the "strategic" principle that allows the learner to analyze the learning task or problem to be solved. According to Le Corre \& al [18] a pedagogical scenario in the VRLEs allows to organize the training for a pedagogical purpose, however the scenario is designed for any learner without considering the individualities, which can slow learning. These authors [18] identified some weaknesses of the Intelligent Tutorial System (ITS) PEGASE for learning with virtual reality [19] and identified its lack of connection with the pedagogical scenario, its lack of modularity and its lack of individualization. To fill these weaknesses, they proposed an ITS called CHRYSAOR based on POSEIDON. This new proposal allows to define a pedagogical scenario and in order to perform it with MASCARET, it will be considered as a knowledge base for the agents. Based on the study of these research works, we noticed that the pedagogical models are planned at the early environment's design stages and all the possible pedagogical situations must have been considered in advance.

\subsection{Architecture of VRLEs}

In this part we studied different VRLEs' software architectures. Lanquepin \& al [20] propose a platform called HUMANS (Human Models based Artificial eNvironments Software), a generic framework designed to build custom virtual environments. This approach involves the dynamic computation of situations that varies according to pedagogical goals, moreover, it is not easy to handle by non-computer specialists. It is interesting to note that this platform proposes a set of software covering the VRLE life cycle from the design to its exploitation by the learners and trainees. Gerbaud \& al [21] offer a technical infrastructure not for trainers but for engineers seeking to develop VRLEs, by reusing existing components. A first study of these architectures led us to note that they do not address the problem of the design (adaptation or reuse) and operationalization of the scenario models directly by the trainers according to their pedagogical situations.

\section{Analysis of existing VRLE tools}

From the previous literature study, we covered VR tools and environments according to the two main objectives of this research work: the tools that help the teachers to design and generate their own VRLE and design their pedagogical activities. We selected some criteria from the literature [10] to characterize VR tools and design process models. Table 1 and 2 illustrate the results of the study we conducted. 


\subsection{Support for teachers to generate a VRLE}

We study in this part the question concerning the support for teachers to produce their own VRLE. What is the process? Is this process repeatable ${ }^{1}$, reusable or deployable [22]? Is the process teacher-oriented? Table 1 presents the resulting analysis that ensures this objective, for the selected tools: VTS Editor, GVT, ARVAD, HUMANS and MASCARET. VTS Editor [23] allows generating simulation-type serious games. The designer creates scenarios with an intuitive graphical editing mode based on block settings (QCM, Q\&A, images, virtual characters, scoring, statistics, etc.). The designer can get a preview of his current creation and change what he has already designed. The VTS design process is both repeatable and reusable. Nevertheless, from the first use of VTS, we find out that it is intended for pedagogical engineer and elearning project managers. Economically, VTS is very expensive compared to other simulation tools. Generic Virtual Training (GVT) [21] is a platform to create virtual environments for procedural training. It aims at improving technical training overall, in terms of productivity and qualification, and exploiting new potential, design, monitoring and capitalization of educational pathways. The GVT platform is based on visual metaphors. This concept is important in our research situation because it focuses on interactions with objects using a menu of icons representing possible interactions between the object and the user. GVT design process focuses on three elements: modeling an actor's activity, modeling the collaborative scenario and setting up an action selection mechanism. Its model allows reproducing or realizing new pedagogical situations oriented in the industrial sector, but their deployment is partial.

\begin{tabular}{|c|c|c|c|c|}
\cline { 2 - 4 } \multicolumn{1}{c|}{} & \multicolumn{3}{c|}{ Define a design process model } & Teaching ori- \\
\cline { 2 - 4 } \multicolumn{1}{c|}{} & Repeatable & Reusable & Deployable & no \\
\hline GVT & $y e s$ & yes & Partial & yes \\
\hline ARVAD & $n o$ & yes & Partial & partial \\
\hline HUMANS & $y e s$ & $y e s$ & No & no \\
\hline MASCARET & $y e s$ & yes & No & no \\
\hline VTS Editor & $y e s$ & yes & Yes & \\
\hline
\end{tabular}

Table 1. Support for teachers to generate VRLE

The main focus of ARVAD's project [24] was on the design activity of pedagogical scenario models by teachers themselves and their operationalization in a VR environment. The ARVAD project aim is rather similar to this current research work but the public concerns exclusively LUSI (Local Units for School Inclusion) students to enable them to be more autonomous in their personal and professional life. As it is a work in progress, the design process proposes a reusable but not repeatable (generic) approach. Also, the effort required for operationalization still remains semi-automatic to deploy a new scenario, the teacher having to set variables in text files.

The major disadvantage of GVT and ARVAD environment is that they offer pedagogical models which depend on a particular learning field and training context.

\footnotetext{
${ }^{1}$ The necessary process discipline is in place to repeat earlier successes on projects with similar applications.
} 
MASCARET is a MultiAgent System for Collaborative, Adaptive \& Realistic Environments for Training [17]. It defines an application design process repeatable and reusable and ensures a high level of abstraction when designing. It provides a language that allows an expert to define both the environment and the activities which are performed in that environment and provides operational semantics to each language concept, which automatically creates the simulation in a VR application and is seen as a knowledge base of the agents who perform the activities in the environment. The HUMANS (HUman Models based Artificial eNvironments Software) platform is a generic framework designed to build virtual environments. It " can be adapted to different application cases, technological configurations or pedagogical strategies" [20]. As GVT, VTS Editor, the MASCARET and HUMANS design process model allows realizing and repeating pedagogical situations oriented simulation. However these environments do not allow their deployment (except VTS) and cannot be easily handled by teachers.

\subsection{Support for designing pedagogical scenarios}

We study in this section our second question related to the possibility of support offer to the teachers in designing VR-oriented pedagogical model. In our research work, the pedagogical model is represented by a pedagogical scenario in the form of a workflow of activities. Therefore, we are asking if models of scenario in a VRLE are generic, if they can be transformed in computational model and if they can be reused and adapted to the pedagogical situations. Table 2 presents the resulting analysis of different tools for designing pedagogical scenarios. VTS editor [23] offers a graph-based scenario editor. The notion of the graph allows teachers to design various and nonlinear scenarios, with complex interactions. The graph is a set of icons called "Blocks". They are connected by logical links, represented by lines. Each type of block has its own operation, making it possible to enrich the course of the scenario. Blocks are regular structures that are instances of reusable styles. The Scenario Graph editor contains all the scenes that compose the scenario currently edited. In VTS editor, the pedagogical scenarios are adaptable and reusable for other pedagogical simulation, but they are not generic because they do not allow producing non-oriented simulation situations. The HUMANS platform offers via its SELDON module an approach for adaptive scenario [20]. The SEDLON model is extrinsic, this means that scenario is seen as an additional step in framing an existing virtual environment, and not as an integral part of the design process for that environment. Its scenario model is partially adaptable, reusable, and operationalizable, but it is intended for direct, behavioral, or motivational control activities, semi-autonomous virtual characters, or instantaneous changes in simulated system states would interfere with behavioral consistency. However, this approach does not offer a scenario editor. The ARVAD [24] environment proposes models of scenario that may offer to the teachers the possibility to define their own scenarios according to the learner's profile and the pedagogical situation. These scenarios are reusable and adaptable with new pedagogical situations but they are not generic. An editor is partially developed. It facilitates the 
design and parameterization of scenarios in virtual environments for learning travel autonomy for LUSI class.

In MASCARET [17], the scenario's model is a virtual agent-oriented. This model is based on four concepts: the organization, the role, the agent and the element of behavior. The organization serves as a structuring factor, providing a framework for interactions of the agents who are part of it. There are two types of organization: social organization and physical organization. Roles are the responsibilities of an agent in the organization. These responsibilities are defined by a set of behavioral elements that must be adopted by the agent playing the role. An agent must have the capabilities to use these behavioral elements (a role therefore imposes prerequisites).

GVT [21] includes mainly a reactive environment composed of behavioral objects, an interaction engine to manage complex interactions (STORM), a scenario engine to manage the course (LORA) and pedagogical engine to guide the learner. The LORA (Language for Object Relation Application) model is designed for pedagogical activities used in an industrial context. In this context, procedures and in particular maintenance procedures are very strict (actions have to be performed in exactly the given order), long and complex. GVT scenario model is reusable thanks to its generic model STORM used to describe reusable behaviors for 3D objects and reusable interactions between those objects. It is also adaptable thanks to its scenario language LORA which allows non-computer scientists to author various and complex sequences of tasks in a virtual scene.

\begin{tabular}{|c|c|c|c|c|c|}
\cline { 2 - 5 } \multicolumn{1}{c|}{} & \multicolumn{4}{c|}{ Define a scenario model } & Propose \\
\cline { 2 - 5 } \multicolumn{1}{c|}{} & Generic & Adaptable & Reusable & Operationalizable & aditor \\
\hline GVT & yes & yes & yes & Yes & partial \\
\hline ARVAD & no & yes & yes & Yes & partial \\
\hline HUMANS & partial & partial & yes & Yes & yes \\
\hline MASCARET & yes & yes & yes & No & no \\
\hline VTS Editor & no & yes & yes & Yes & yes \\
\hline
\end{tabular}

Table 2. Support for designing pedagogical scenario

\section{Proposition of an engineering process teacher-oriented: From design to generation of VRLE}

Our goal is to propose a solution to support and guide teachers and trainers in producing VRLEs adapted to their needs. We define a process of several steps from the definition of the learning situation to its deployment/operationalization in the VR environment (Fig. 1) based on the scenario design process model in [25]. At the beginning of the process, trainers expressed their needs according to their learning situation, with the help of a virtual reality scenario model. Therefore, this step involves in the formalization of the learning situations. A good way to formalize teacher's needs is to use a pattern-based approach. A pattern-based formalization, considering its semi-structured data, allows teachers-designers to express their pedagogical needs without extensive loss of semantic information while representing their pedagogical 
intention with a pattern-based editing tool [26] [27]. Then, we suggest creating pedagogical scenario that defines an orchestrated sequence of learning activities within this formalism. The second step consists in identifying the virtual reality needs (the 3D environment and the virtual reality tools to use). In this step, teacher-designer or community of teachers chooses and adapts a virtual reality environment where a pedagogical scenario is instantiated. The questions we have to deal with are: (1) which architecture we shall use to create this service (2) How we insure the interoperability of the various 3Ds environments? (3) How we shall face the limits of compatibility of the technical components? At this stage, the difficulty is to provide virtual-reality tools and environments teachers-friendly that teachers may use by themselves for specifying their learning needs. The third step "Operationalization" consists in deploying a pedagogical scenario in the selected virtual reality environment. The main activity consists in operating the scenario on the chosen environment. With this step the generation of a new VRLE or evolution of existing one is possible, based on teacher's needs. We shall study in this step the feasibility of a service, which will allow the operability of any scenario on any adapted 3D environment. The fourth step "Tests" focuses on the simulation and testing activities to adapt the selected VRLE. Finally, after the learning step, we propose to analyze the tracking data recovered from the test and learning steps to anticipate as possible the future adaptations and modifications of VRLE. Within this last step, we enforce an adaptation process from the tests and learning tracks to adapt to the teachers' needs.

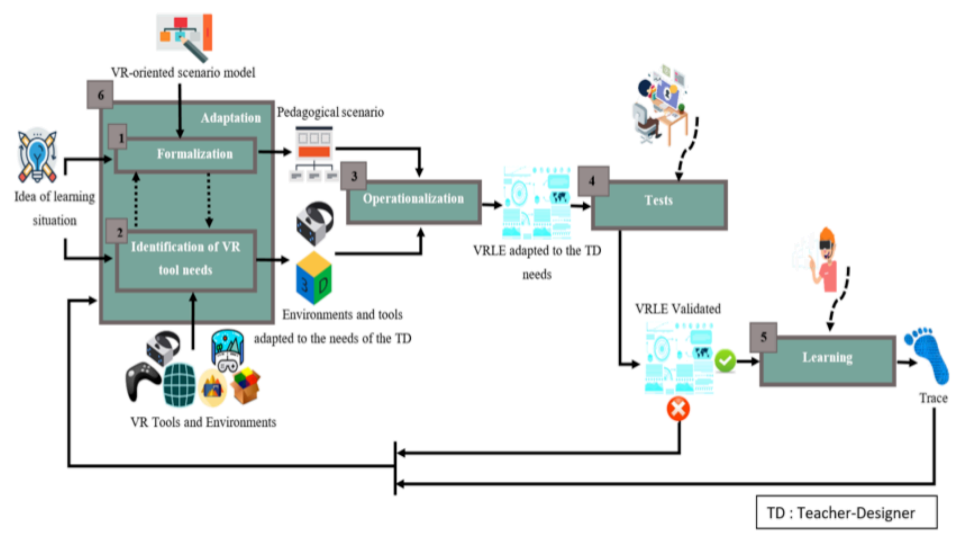

Fig. 1. A process of design and production of VRLE

In the next part, we illustrate this process on a case study. First, the teacher comes with an idea of learning scenario, expresses and formalizes it thanks to an editor. The system generates a structured and adaptable/reusable scenario as a pattern. Then the teacher selects an already existing 3D environment. The adaptation service has to apply the necessary features to return the compatible environment and send it to the integration's service. The latter will instantiate the scenario on the chosen environment and generate the new adapted VRLE. 


\section{$5 \quad$ A process instantiation of a pedagogical situation}

A learning situation (also known as a pedagogical situation), is a set of conditions and circumstances that can lead a person to build knowledge. An instantiation of pedagogical situation from our design process was made with a physics teacher in French college. He can be considered as non-expert designer since, on the one hand, he has not participated in the design of the first version of models and tools that we propose, and, on the other hand, he is not an advanced user of computer sciences. A teacher's design of a pedagogical situation involves the expression of a need in a disciplinary context and a goal to be achieved for the learners. The expressed need is to show students the phenomenon of relativity of movement and the gravitational attraction. The pedagogical objectives are the following: Observation of the Moon's movement relative to the Earth (circular movement); Observation of the Moon's movement relative to the Sun (curvilinear movement); Observation of the Moon's movement relative to itself (rotation-synchronous revolution); Understand the formula of gravitational attraction force $\left(\mathrm{F}=\mathrm{G} * \mathrm{M}\right.$ Earth * M Moon / Distance $\left.{ }^{2}\right)$.
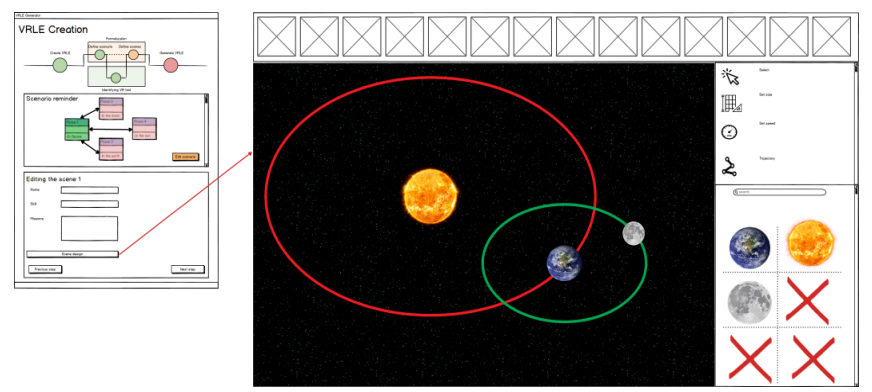

Fig. 2. Overview of the scenario editor

After this work, the teacher can begin the design process by the formalization stage in which we propose a VR-oriented scenario editor that allows the teacher's ideas to be formalized in a computational language (Fig. 3). The editor allows the definition of the scenario and its scenes. The teacher can either create his own personalized scenario or choose an existing VR-oriented scenario model and modify its content according to the needs. The scenario is a series of scenes where each scene is characterized by a name, skills and missions. Indeed, the teacher specifies the scene he wants to use in order to reinforce the learner's knowledge or skill and define the missions that the learner will have to do. The activities of the scenario will be the exercises proposed in each scene. There will be four scenes: space, Earth, Sun and Moon. The learner will have hypotheses representing the different possible movements and it is up to him to choose which one corresponds to the true phenomenon of the moon's movement in relation to the earth, the sun and in relation to itself. With each correct answer, the student can move on to the next exercise. Finally, the editor generates an XML file. This file will be used in the next operationalization phase. 
After the formalization phase, the teacher identifies his needs for VR tools and objects. A VR tool is a VR-specific hardware interface, which have been booming and the public's craze for interactive virtual worlds [28]. We propose in this step a module for the selection of the VR tools by the teacher. He will also need to identify also all VR objects. VR objects can be pedagogical objects or artifact objects. A pedagogical object is a semantic unit of learning resources. It can be an exercise, a definition, examples, etc. Each pedagogical object can gather elementary components like an image named "component" (or "asset"). It may also be composed of other pedagogical objects. At first, the teacher selects VR tools he needs from the list. In our case the teacher will only need a VR headset. In a second step, he defines VR objects. The virtual environment corresponding to this teaching situation is space. The Earth, the Moon and the Sun represent the VR objects of this environment. It is possible to move the planets by simply "drag and drop" in the scene. It will also have a parameter button to handle the background of the scene. Subsequently, the teacher modifies certain parameters: he sets the size, speed and trajectory of each object. Thus, he animates the scene and sets the pedagogical objectives. Indeed, the idea of the teacher is to allow the learner to move on one of these objects to observe which objects revolve around another object.

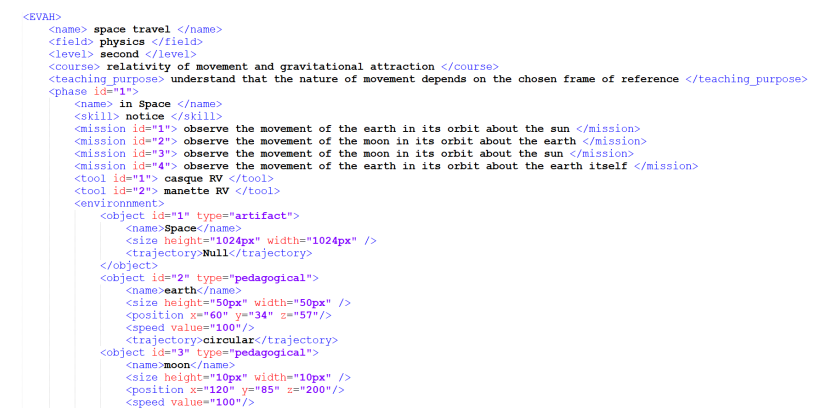

Fig. 2. XML file modeling the formalization and the virtual environment identification stage

Below (Fig.2) is an example of the XML file resulting from the part of the scenario where the objective of the task asked to the students is to observe the movement of the Sun relative to the Moon (curvilinear movement). Subsequently, we identify a phase of operationalization resulting from the adequacy between the two previous phases (formalization and identification). The goal of the operationalization stage is to generate a VRLE. Once the operationalization is done, the teacher enters the stage of simulations and tests. This phase allows the simulation of the generated VRLE. Next, the teacher tests whether his learning objectives are achieved: Has the student been able to understand the notion of gravitation? Did the student also know how to calculate the gravitational attraction force that depends on mass and distance? Then the teacher compares the test results with the desired results during the learning phase and may apply an adaptation stage from the test traces when the results do not correspond to the pedagogical needs. The adaptation will be either at the level of the formalization of the needs, or at the level of the identification of tools and VR objects. 


\section{CONCLUSION}

In this article we proposed a design process framework model of VRLE for teachers/designers. Our challenge is to facilitate the design of pedagogical scenarios and their integration/operationalization/deployment in various virtual reality environments by the teachers themselves without being constrainted by the technical difficulties, which are related to the use of technology in a virtual reality environment. This work is in progress. Future works will be dedicated to the design of at least two learning situations and the development of a technical solution and the instantiation of the process on these learning situations. A tool, a graphic-editor-like will be developed to support the design process and provide a "proof-of-concept" of the proposed approach. Last but not least, extra effort will be required to implement, evaluate and improve the approach in other pedagogical situations in the design process editor.

\section{$7 \quad$ References}

1. T. A. Mikropoulos, A. Chalkidis, A. Katsikis and A. Emvalotis, "Students' attitudes towards educational virtual environments". Education and Information Technologies, vol. 3, no. 2, pp. 137-148, 1998.

2. C. J. Chen, "Theoretical Bases for Using Virtual Reality in Education". Themes in Science and Technology Education, vol. 2, no. 1-2, pp. 71-90, 2010.

3. K. Carpentier and D. Lourdeaux, "Generation of Learning Situations According to the Learner's Profile Within a Virtual Environment". Communications in Computer and Information Science, pp. 245 - 260, 2014.

4. K. Sehaba and A. M. Hussaan, "Adaptive serious game for the re-education of cognitive disorders". AMSE Journals, Advances in modeling, series Modelling C, vol. 3, no. 73, pp. 148-159, 2013.

5. P. Mishra and M. J. Koehler, "Technological pedagogical content knowledge: A framework for teacher knowledge". Teachers college record, vol. 108, no. 6, pp. 2017, 2006.

6. P. Goodyear, "Teaching as design". HERDSA Review of Higher Education, pp. 27-50, 2015.

7. D. Hernández-Leo, S. Agostinho, M. Beardsley, S. Bennett and L. Lockyer, "Helping teachers to think about their design problem: a pilot study to stimulate design thinking". 9th annual International Conference on Education and New Learning Technologies EDULEARN17, Barcelona, Spain, 2017.

8. S. Bennett, S. Agostinho and L. Lockyer, "The process of designing for learning: understanding university teachers design work". Educational Technology Research and Development, vol. 65, no. 1, pp. 125-145, 2017.

9. E. Tan and K. D. Könings, "Teachers as participatory designers: two case studies with technology-enhanced learning environments". Instructional Science, vol. 43, no. 2, pp. 203-228, March 2015.

10. B. Zeiss, D. Vega, I. Schieferdecker, H. Neukirchen and J. Grabowski, "Applying the ISO 9126 Quality Model to Test Specifications - Exemplified for TTCN-3 Test Specifications", pp. 231-244, 2007.

11. T.-H. Trinh, R. Querrec, P. De Loor and P. Chevaillier, "Ensuring semantic spatial constraints in virtual environments using UML/OCL". VRST '10 Proc. Of the $17^{\text {th }}$ ACM 
Symp. on Virtual Reality Software and Technology, pp. 219-226, Hong-Kong, Nov. 2224, 2010.

12. C. J. Chen, S. C. Toh and W. M. Fauzy, "The Theoretical Framework for Designing Desktop Virtual Reality-Based Learning Environments". Journal of Interactive Learning Research, vol. 15 (2), 147-167. Norfolk, VA: Association for the Advancement of Computing in Education (AACE), 2004.

13. C. J. Chen and C. S. Teh, "Enhancing an Instructional Design Model for Virtual RealityBased Learning". Australasian Journal of Educational Technology, 29 (5), 699-716, 2013.

14. L. T. Ritz, "Teaching with CAVE virtual reality systems: Instructional design strategies that promote adequate cognitive load for learners". SMTC Plan B Papers. 5, 2015.

15. N. Marion, R. Querrec and P. Chevaillier, "Integrating Knowledge from Virtual Reality Environments to Learning Scenario Models-A Meta-modeling Approach". Proceedings of the 1st International Conference on Computer Supported Education, PP. 254-259, 2009.

16. M. Fahim, A. Jakimi and L. El Bermi, "Pedagogical Scenarization for Virtual Environments for Training: Towards Genericity, Coherence and Adaptivity". International Journal of Advanced Engineering Research and Science, vol. 3, no. 12, pp. 96-103, 2016.

17. C. Buche, R. Querrec, P. De Loor and P. Chevaillier, "Mascaret: Pedagogical multi-agents system for virtual environment for training". Journal of Distance Education Technologies, vol. 4, no. 2, pp. 41-61, 2004.

18. F. Le Corre, C. Hoareau, F. Ganier, C. Buche and R. Querrec, "A Pedagogical Scenario Language for Virtual Environment for Learning based on UML Meta-model. Application to Blood Analysis Instrument". Proceedings of the 6th International Conference on Computer Supported Education (CSEDU), pp. 301-308, Spain, 2014.

19. C. Buche, C. Bossard, R. Querrec and P. Chevaillier, "PEGASE: A generic and adaptable intelligent system for virtual reality learning environments". International Journal of Virtual Reality, vol. 9, no. 2, pp. 73-85, 2010.

20. V. Lanquepin, K. Carpentier, D. Lourdeaux, M. Lhommet, C. Barot and K. Amokrane, "HUMANS: a HUman Models based Artificial eNvironments software platform". VRIC'13, Mar 13, Laval, France, pp. 59-68, 2013.

21. S. Gerbaud, N. Mollet, F. Ganier, B. Arnaldi and J. Tisseau, "GVT: a platform to create virtual environments for". in Virtual Reality Conference, Reno, NE, USA, 2008.

22. The process approach in iso 9001:2015, International Organization for Standardization.

23. G. RUZZU, "Blog VTS Editor authoring software for Degital Learning". Serious factory, 8 December 2017. [Online]. Available: https://www.seriousfactory.com/virtual-trainingsuite/?lang=en.

24. L. Oubahssi and C. Piau-Toffolon, "Virtual learning environment design in the context of orientation skills acquisition for LUSI class". CSEDU 2018, the International Conference on Computer Supported Education, Funchal, Madeira, Portugal, pp. 47-58, 2018.

25. V. Emin-Martinez, C. Hansen, R. Triana, M. Jesus, B. Wasson, Y. Mor, M. Dascalu, R. Ferguson and J.-P. Pernin, "Towards teacher-led design inquiry of learning". eLearning Papers, no. 36, pp. 1-12, 2014.

26. Z. Tadjine, L. Oubahssi, C. Piau-Toffolon and S. Iksal, "A process using ontology to automate the operationalization of pattern-based learning scenarios". Communications in Computer and Information Science (CCIS), pp.444-461, Springer-Verlag, 2016.

27. Y. Mor, "Embedding design patterns in a methodology for a design science of eLearning". Christian Kohls \& Joachim Wedekind, ed., 'Problems Investigations of ELearning Patterns: Context Factors Solutions', 2010.

28. P. Fuchs, G. Moreau and P. Guitton, "Virtual reality: concepts and technologies". CRC Press, 2011 